African Journal of Educational Studies in Mathematics and Sciences Vol. 15, No. 2., 2019

\title{
Effect of the constructivists teaching method, undergraduate students' statistics self-concept and other psychological constructs in mediating their motivation for learning statistics
}

\author{
D. Y. Arthur
}

\begin{abstract}
This study sought to model the effect of the constructivists teaching method, learners' statistics self-concept and their psychological constructs (i.e. need for competence, relatedness and autonomy) in mediating undergraduate students' motivation for learning statistics in a Ghanaian university. The study adopted quantitative approach by using simple random sampling techniques. A sample of 107 students from the Faculties of Technical and Vocational Education of the University of Education, Winneba were given questionnaires to measure how the constructivists teaching method and as well as psychological constructs have mediated their motivation for learning statistics. The data obtained were analysed using Structural Equation Modeling (SEM) to estimate model parameters to answer the research questions and test hypotheses. The study revealed that students' psychological need for competence, relatedness and autonomy is positively and significantly influenced by the constructivism teaching approach. Moreover, students' psychological need for relatedness and autonomy positively and significantly affect the students' statistics self-concept. The results further suggested that students' statistics self-concept positively and significantly influences students' motivation to study statistics. The study concluded that the teaching method predicts students' needs for competence $(\mathrm{R} 2=0.189)$, relatedness $(\mathrm{R} 2=0.503)$ and autonomy $(\mathrm{R} 2=0.198)$. In addition, students psychological need for competence, relatedness and autonomy significantly predict $(\mathrm{R} 2=0.630)$ students self-concept in statistics. Finally, students' motivation can be predicted $(\mathrm{R} 2=0.480)$ by constructivism teaching approach using psychological needs and self-concept as mediating variables.
\end{abstract}

Keywords: $\quad$ autonomy; competence; constructivism; relatedness; statistics; students' motivation

\section{Introduction}

The sense of motivation in students' academic life is crucial for learning any subject and it is highly needed for academic success (Toshalis \& Nakkula, 2012). For most students, achievement for success has been the very reason for engaging in learning activities and the quest for achievement is highly supported by their self-determination drive for achievement. (Flink, Boggiano, \& Barrett, 1990; Ryan \& Deci, 2000). Every student goes through the learning activity with the prime aim of success and this success may not materialize without self-determination. Self-determination may emanate from an inward drive that propels individuals' ability for performance and achievement. Goal orientation and achievement may be influenced by individuals feeling of competence, relatedness and autonomy. The need for competence, relatedness and autonomy can, to some extent, influence students' academic self-concept for further influence on their motivation to study a subject. It is interesting to note that lack of self-

Dissou Yarhands Arthur, University of Education, Winneba, College of Technology Education, Department of Mathematics Education, P.O. Box 1277 Kumasi-Ghana. Email: day1981boy@yahoo.com.

Open Access article distributed under the terms of the Creative Commons Attributions License [CC BY-NC-ND 4.0] http://creativecommons.org/licenses/by-nc-nd/4.0. DOI: https://dx.doi.org/10.4314/ajesms.v15ii2.11 
Effect of the constructivists teaching method, undergraduate students' statistics self-concept and other psychological constructs in mediating their motivation for learning statistics

D. Y. Arthur

determination among students in mathematics or statistics may decrease their quest for autonomy, relatedness and competence in mathematics and statistics education in particular. The selfdetermination drive in students is generally influenced by the students' psychological need for autonomy, relatedness and competence. The sense of motivation in students' academic life is crucial for learning any subject and it highly needed for academic success. The section below discusses the psychological need for autonomy, competence and relatedness.

\section{Competence, Relatedness and Autonomy}

In predicting students' outcomes (achievement) and motivation as stipulated by the selfdetermination theory (Deci \& Ryan, 2000), competence, relatedness and autonomy of students are three interrelated basic psychological needs worthy of consideration. Competence, relatedness and autonomy are three interrelated basic psychological needs which could predict student's outcomes (achievement) and motivation as stipulated by the self-determination theory (Deci \& Ryan, 2000).

There is therefore the need for both instructors and parents to support children's competence, relatedness and autonomy in specific discipline. This is supported by some studies (Aunola, Viljaranta, Lehtinen \& Nurmi, 2013) which revealed that maternal support of children's need for autonomy and relatedness affects students' motivation and interest in mathematics. In addition, support for competence such as giving optimal/standard challenges and positive feedback facilitates intrinsic motivation and must be accompanied by support for autonomy, thus indicating the interdependence of the three variables. In contrast, negative feedbacks, which could be selfadministered or interpersonally administered in the form of failure has also been revealed by many studies to decrease intrinsic motivation due to decrease perceived competence and could even lead to serious long-term effects such as students feeling demotivated (Boggiano \& Barrett, 1985).

\section{Constructivism Teaching Approach}

Constructivism teaching approach primarily takes into account the student, helping him or her to internalize and transform new information usually through the creation of new information that usually stems from the emergence of new cognitive structures. This differs from the traditional teaching approach which is a basically a repetitive activity where students eventually regurgitate information in tests. The tenets of constructivist teaching approaching as put forward by Brooks and Brooks (1999) are: a) posing problems of emerging relevance to students; b) structuring learning around primary concepts and the quest for essence; c) seeking and appreciating student's points of view; d) adapting the curriculum to address student's suppositions; and e) assessing student learning in the context of teaching.

Several educational researchers have examined the two teaching approaches vis-à-vis and have come up with contrasting results with regards to the benefits of the two to the learner (Brooks \& Brooks, 1999). However, recent works has demonstrated higher superiority of constructivism teaching approach to traditional approach. The study by Nie and Lau (2010) which compares constructive and didactic instructor with some learning variables revealed constructivist instruction was a significant positive predictor of students deep processing strategies, self-efficacy, task value, and English achievement while didactic instruction significantly promoted student surface processing strategies and poor English achievement among students (Nie \& Lau, 2010). Similarly, the study by Kim (2005) revealed that constructivist teaching was more effective than traditional teaching in terms of academic achievement. In addition, it was concluded that in relation to self-control and learning strategies, constructivist teaching did not yield any effect but had a significant effect on motivation, anxiety towards learning and self-monitoring. However, the study showed that constructivist environment was preferred to a traditional classroom supporting 
the need to train the next generation of children/students in apt learning and teaching environments (Kim, 2005). Moving forward, it is important that educators give up the single focus on students' grades but challenge students to explore the array of the world's complexity and encourage them to ask questions and ignite creativity and problem-solving skills. Therefore, there is the urgent need that we retrain the teacher as a constructivist who was previously under the traditional teaching approach where the instructor assumes the predominate role in the classroom as well as the archaic use of textbooks (Kim, 2005).

\section{Academic Self-Efficacy}

According to Bandura (1971), self-efficacy encompasses beliefs in one's capabilities to organize and execute the series of actions required to produce given attainments. Consequently, these beliefs affect the people's choices of activities, the amount of time, energy, effort and resources put in in such activities, their perseverance in the face of obstacles and failures and their resilience even in the face of adversity. Furthermore, Schunk (1991) defines academic self-efficacy as individuals' conviction that they can successfully perform given academic task at various levels. While self-concept explores the skills and abilities possessed by individuals, self-efficacy on the other hand considers more importantly what individuals believe they can do with whatever skills or abilities they may possess (Bong \& Skaalvik, 2003). In fact, both self-concept and efficacy could predict students' academic engagement, goal setting, task choice, persistence and effort, intrinsic motivation, strategy use, performance and achievement, as well as career selection.

\section{Self-Concept}

Student's self-concept, particularly in mathematics as a subject has been an active area of research for some time now since this construct could serve as a predictor to academic achievement and a wide range of motivation indicators (Githua \& Mwangi, 2003; Mohamed \& Waheed, 2011). Children with different self-beliefs show different levels of cognition, social and emotional engagement in school (Bong \& Skaalvik, 2003). However, an important research area is gender differences in student self-concept and studies that have explored such research area have revealed that girls have lower self-concept than boys in mathematics (Skaalvik \& Skaalvik, 2004). In addition, boys have higher mathematics performance expectations than girls suggesting that boys tend to judge themselves more positively in mathematics as a subject than girls (Skaalvik \& Skaalvik, 2004). This result is also in agreement with other studies which revealed the general perception that mathematics is a masculine subject (Frost, Hyde \& Fennema, 1994; Lindberg, Hyde, Petersen \& Linn, 2010). On the other hand, the environment also plays a role in the development of self-concept and one of the major factors that contribute to low self-concept of students is the use of physical force or corporal punishment in schools as reported by Straus and Paschall (2009).

\section{Students' Motivation and Self-Determination.}

Motivation is one of the major personal and psychological variables that plays a significant role in educational success and almost any activity (Tella, 2007). This variable has therefore received lots of research attention, particularly with mathematics education, largely due to the worrying landscape of students' mathematics outcome. In fact, educational psychologists believe that motivation is a necessary ingredient for learning (Biehler \& Snowmnan, 1986). Therefore, its absence or insufficiency could jeopardize recent efforts towards achieving universal education goal, one of the key tenets of the now sustainable development goals. It therefore becomes important for all stakeholders involved with students' education to devise novel strategies (while strengthening existing ones) to boost students' motivation in mathematics. Instructors must create 
Effect of the constructivists teaching method, undergraduate students' statistics self-concept and other psychological constructs in mediating their motivation for learning statistics

D. Y. Arthur

a friendly environment that supports students learning while taking into account learner differences and background characteristics. Moreover, parental support needs to be encouraged and educational policy makers advocate the right policies to support learning. On the other hand, when a behaviour is self-determined, the regulatory process is a choice, but when it is controlled, the regulatory process is compliance or even defiance in certain instances (Deci, Vallerand, Pelletier \& Ryan, 1991).

\section{Intrinsic and Extrinsic}

The type of motivation whereby individuals spontaneously engage in a particular activity or behaviour usually for pleasure, satisfaction or fulfilment derived from performance is termed as intrinsic motivation (Edward \& Ryan, 1985). Several educational psychologists argue that intrinsic motivation is characterized by mastery orientation and the tendency to seek out novel strategies and challenging learning approaches to accomplish a specific task (Gottfried, Fleming \& Gottfried, 1994; Harter, 1981). In actual fact, individuals that are intrinsically motivated towards a particular activity or task do so without any expectation of material rewards or constrains; thus, such activities are done willingly for the love of doing it. For instance, a student who appreciates and loves to solve mathematics questions largely due to some innate pleasure is intrinsically motivated and would therefore always want to try such questions. Conversely, extrinsically motivation behaviours are performed not because of any inherent interest in the activity but due to necessity or some separable consequences. A classic example of extrinsic motivation is when a student learns because he needs to pass a test (and or avoid the consequences of failure) in order to qualify for promotion to the next level or class. However, previous studies that investigated self-determination and motivation among students have revealed that both intrinsic and extrinsic motivation affect students' attitude such as attendance and participation in school and classroom activities, and some learning outcomes such as higher academic performance. Moreover, studies that investigated gender differences showed that girls have higher intrinsic motivation for language studies than boys and lower intrinsic motivation for mathematics as a subject than boys (Skaalvik \& Skaalvik, 2004). The problem of determining the impact of constructivist approach to teaching and learning of statistics on students' motivation in learning statistics as mediated by students' statistics self-concept exist and undermined. This study is crucial for urgent intervention to bridge the gap in literature by investigating the influence of psychological needs on students' statistics self-concept. The study would contribute and update literature on these variables and their contribution to students' motivation in statistics literature and further explain the contribution of these psychological needs on students' motivation.

\section{Conceptual Framework}

The study presents a conceptual framework in Fig. 1. In this framework, it is conceptualised that constructivist approach in statistic teaching (CAST) influence students' psychological need of competence, relatedness and autonomy. These students' psychological needs influence students' statistics self-concept and the students' statistics self-concept influence student motivation in learning statistics. The Fig. 1 further suggests the mediation role of students' psychological needs and students' statistics self-concepts in predicting students' statistics self-concept and students' motivation respectively. 
African Journal of Educational Studies in Mathematics and Sciences Vol. 15, No. 2., 2019

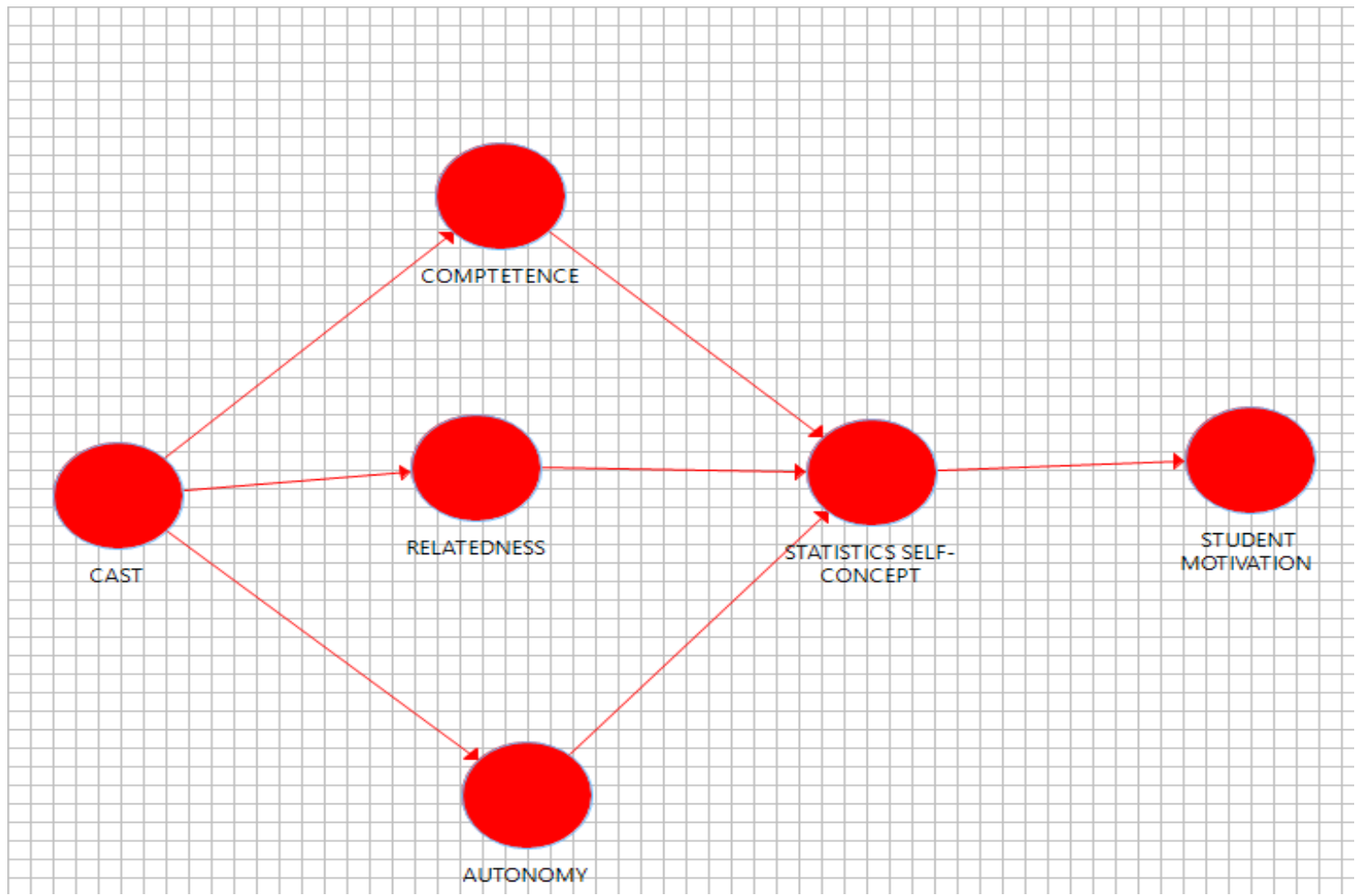

Fig 1 Conceptual Model for students' motivation for learning Statistics

\section{Research Objectives.}

This study presents the following specific objectives

i. To determine the effect of constructivists teaching approach on students' competence, relatedness and autonomy in learning statistics.

ii. To investigate the extent to which student feeling of competence, relatedness and autonomy affects students' academic self-efficacy in statistics.

iii. To determine the effect of students' academic self-efficacy on students' motivation in learning statistics.

\section{Research Hypothesis}

The following research hypotheses were derived from the research objectives.

H1: Constructivists teaching approach positively and significantly affects students feeling of competence, relatedness and autonomy.

H2: Students' feeling of competence, relatedness and autonomy affect students' academic selfefficacy positively and significantly.

H3: Students' academic self-concepts influence students' motivation for learning statistics positively and significantly. 
Effect of the constructivists teaching method, undergraduate students' statistics self-concept and other psychological constructs in mediating their motivation for learning statistics

D. Y. Arthur

\section{Research Methodology}

The study used researcher-designed structured questionnaire to understand the effects of constructivist teaching method, students' feeling of competence, relatedness and autonomy as well as students' academic self-efficacy on students' motivation for learning statistics in a selected Ghanaian tertiary institution. The study involved 107 students from the Faculty of Technical and Faculty of Vocational Education of the University of Education, Winneba. The study used random sampling technique to select students from six departments who took statistics and probability as a borrowed course during the second semester of 2016/2017 academic year. The students' who gave their consent to participate in the study were interviewed personally given the structured questionnaire. The study adopted mix-mode design in the sense that, this study will seek to explore the influence of the understudied constructs, describe the type of relationship that exist and their extent and finally explain the relationships that exists between under studied constructs in line with their effects among the various constructs under study.

The quantitative approach was used for this study and fully completed questionnaires were analysed using descriptive and inferential statistical approach. The study adopted the use of percentages, mean, standard deviation as well as relative importance index in a table for the descriptive statistical techniques while partial least square structural equation model and chisquare test of independence were the inferential statistical tools deplored for the realization of the set objectives.

\section{Results}

The study tested the overall reliability of the measurement and obtained Cronbach's alpha of 0.94 which proved to be extremely reliable. The examination of both discriminant and convergent validity to ascertain the extent to which the indicators measure the constructs was also performed as shown in Fig 1 and Fig. 2. These models were modified to achieve the as shown in in Fig. 4 and Fig. 5. Assessment of convergent and discriminant validity using the Cronbach's alpha produced values, composite reliability as well as the average variance extracted (AVE) were performed. The assessment of convergent and discriminant validity using Cronbach's alpha produced values were acceptable for almost all the constructs with Cronbach's alpha value more than 0.7 with the exception student self-concept that have Cronbach's alpha value less than 0.7. This result indicates that using the Cronbach's alpha criteria all constructs with the exception of student self-concept are reliable. Due to the conservative nature of the Cronbach's alpha value, the use of composite reliability is assumed to be a better measure of discriminant and convergent validity as compared to the Cronbach's alpha. The results from the assessment of the composite alpha reliability values showed that all constructs proved reliable with composite alpha values above 0.7 as indicated in Table 1. The Average Variance Extracted (AVE) was finally used to assess the convergent validity. It was further found that all constructs were discriminant and convergently valid with AVE values above the recommended cut-off of 0.5 as proof of convergent validity as shown in Table 1. 
African Journal of Educational Studies in Mathematics and Sciences Vol. 15, No. 2., 2019

Table 1 Test of Construct Reliability and Validity

\begin{tabular}{lcccc}
\hline \multicolumn{5}{c}{ Test of Construct Reliability and Validity } \\
\hline & $\begin{array}{c} \\
\text { Cronbach's } \\
\text { Alpha }\end{array}$ & rho_A & $\begin{array}{c}\text { Composite } \\
\text { Reliability }\end{array}$ & $\begin{array}{c}\text { Average Variance } \\
\text { Extracted (AVE) }\end{array}$ \\
Autonomy & 0.770 & 0.775 & 0.853 & 0.593 \\
Competence & 0.842 & 0.875 & 0.893 & 0.676 \\
Motivation & 0.791 & 0.804 & 0.857 & 0.546 \\
Relatedness & 0.788 & 0.792 & 0.863 & 0.612 \\
Self-Concept & 0.672 & 0.673 & 0.820 & 0.603 \\
Teaching Approach & 0.805 & 0.812 & 0.872 & 0.632 \\
\hline
\end{tabular}

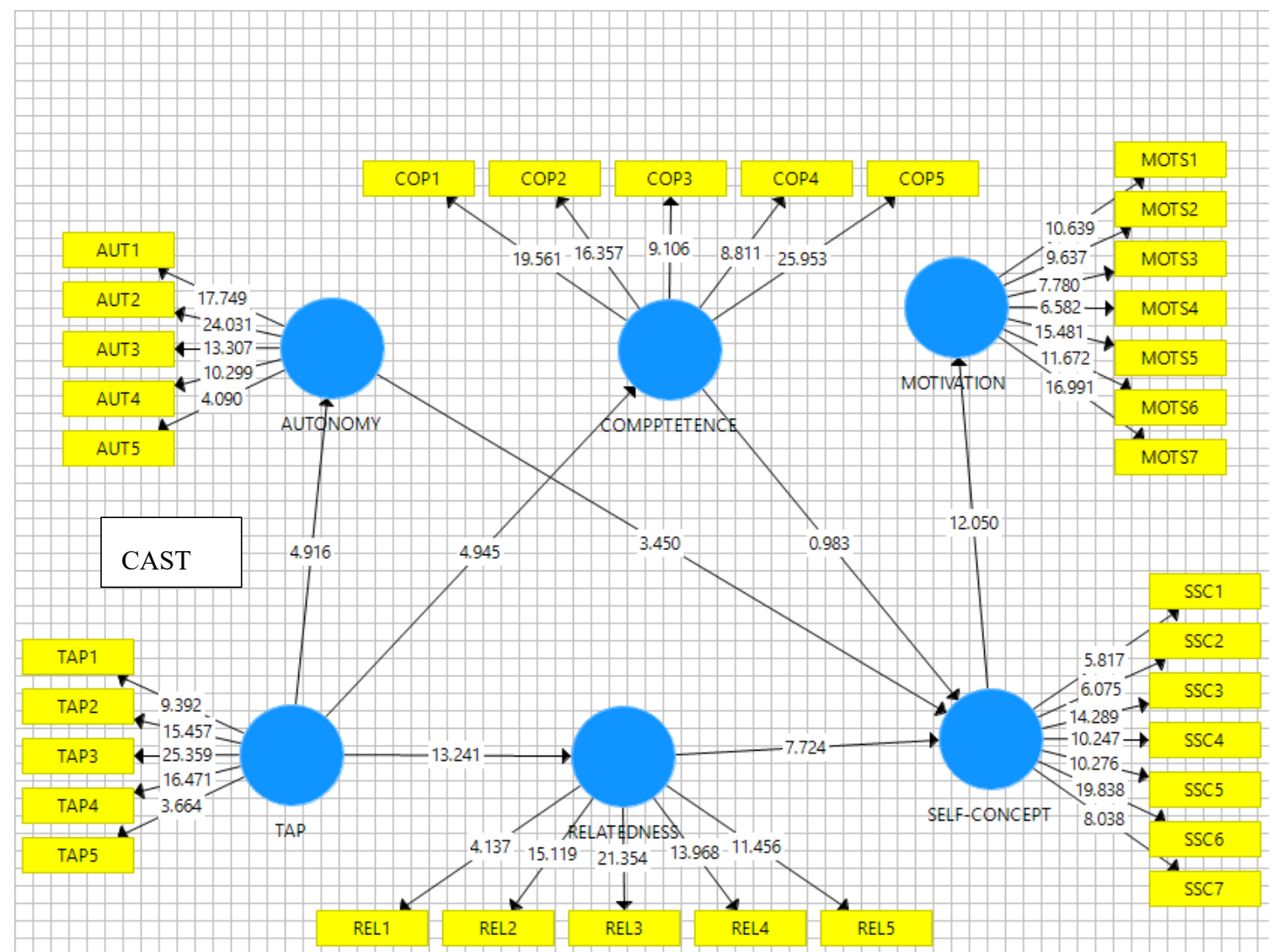

Fig. 2 Empirical Model for Students' Motivation for Learning Statistics 
Effect of the constructivists teaching method, undergraduate students' statistics self-concept and other psychological constructs in mediating their motivation for learning statistics

D. Y. Arthur

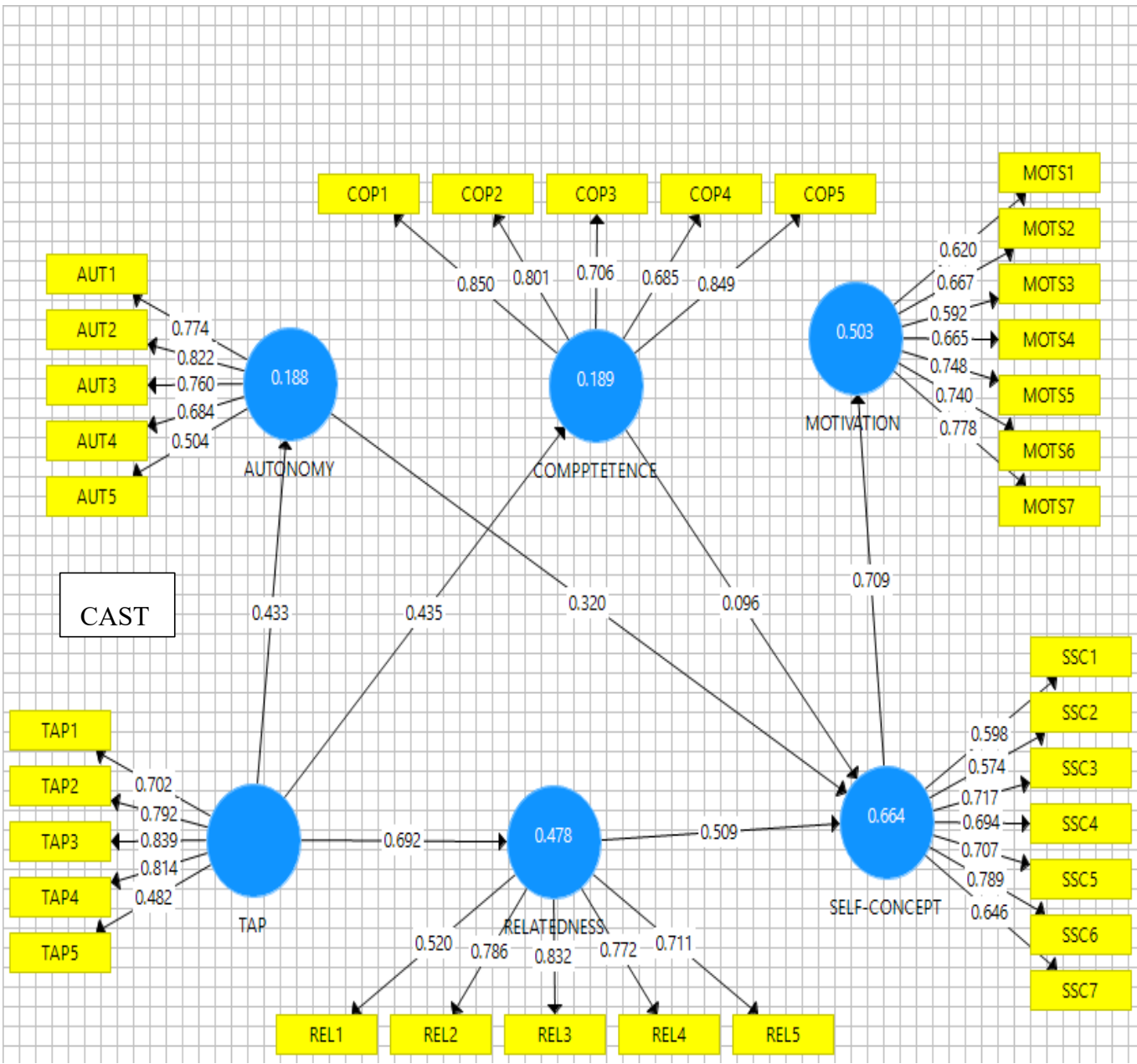

Fig. 3 Bootstrap Empirical Model for Students' Motivation for Learning Statistics 
African Journal of Educational Studies in Mathematics and Sciences Vol. 15, No. 2., 2019

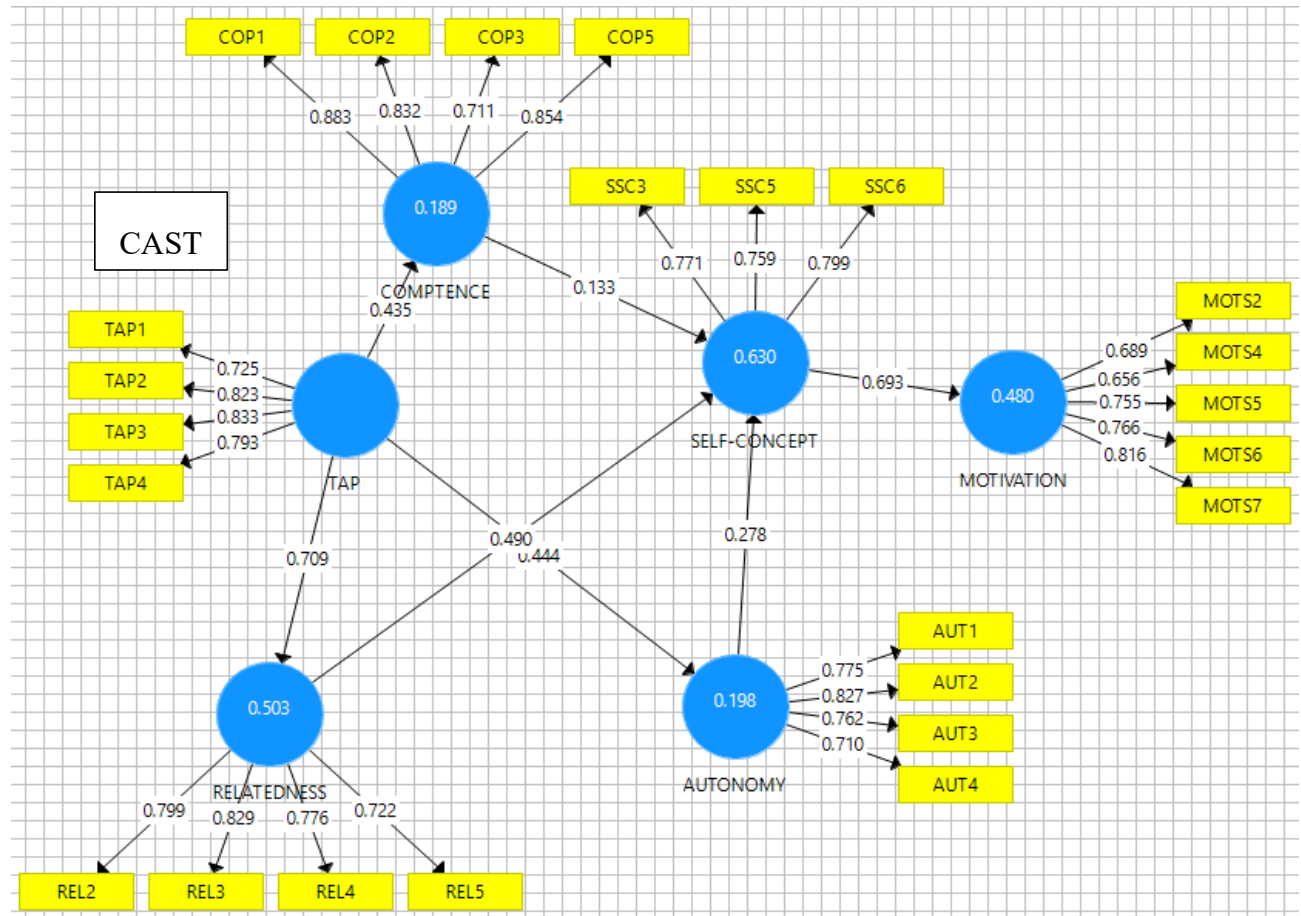

Fig. 4 Modified Empirical Model for Students' Motivation for Learning Statistics

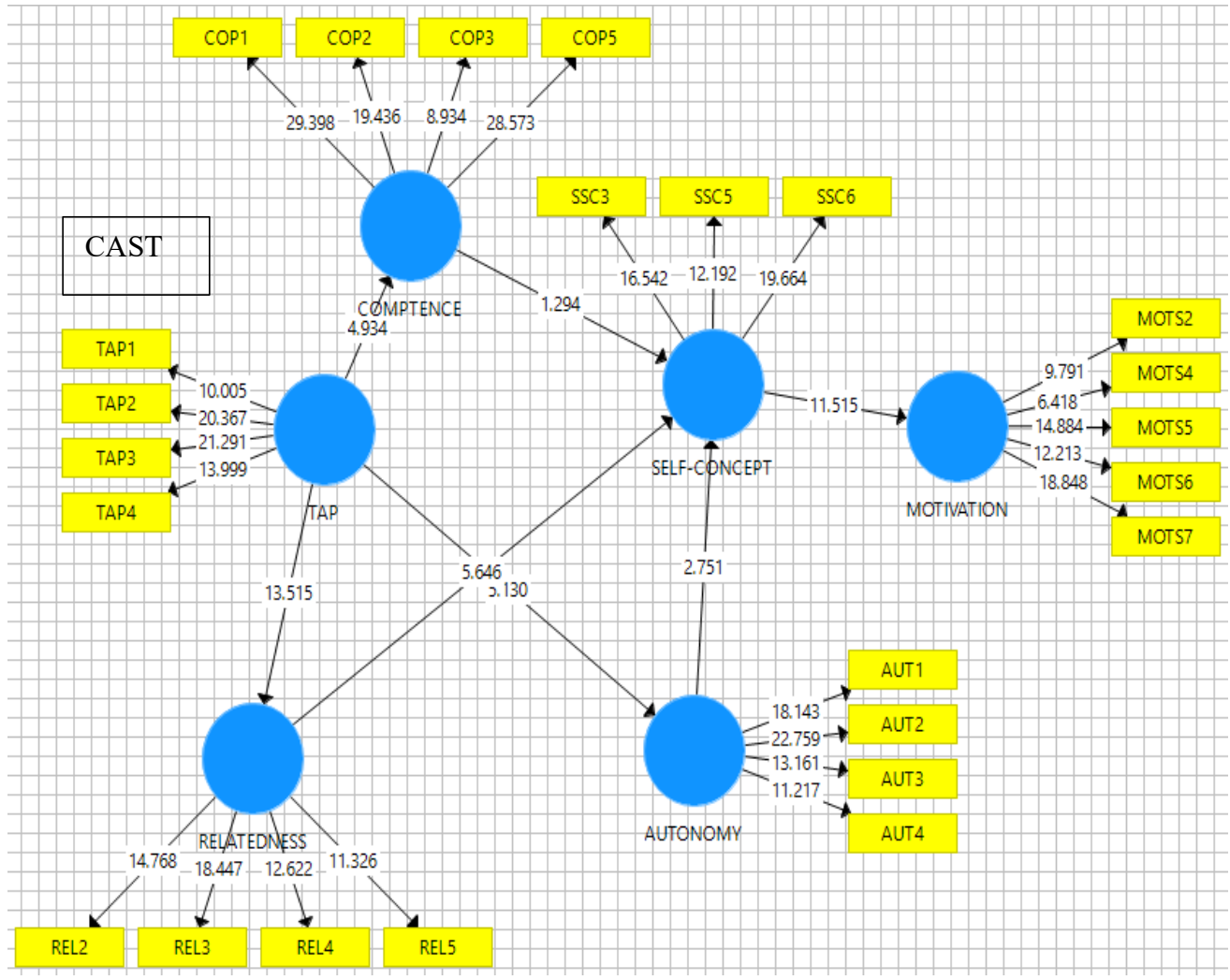

Fig. 5 Modified Bootstrap Empirical Model for Students' Motivation for Learning Statistics 
Effect of the constructivists teaching method, undergraduate students' statistics self-concept and other psychological constructs in mediating their motivation for learning statistics

D. Y. Arthur

Table 2 Fornell-Larcker Criterion for Discriminant Validity

\begin{tabular}{lcccccc}
\hline Construct & Autonomy & $\begin{array}{c}\text { Compe } \\
\text {-tence }\end{array}$ & $\begin{array}{c}\text { Motiva } \\
\text {-tion }\end{array}$ & $\begin{array}{c}\text { Related- } \\
\text { ness }\end{array}$ & $\begin{array}{c}\text { Self- } \\
\text { Concept }\end{array}$ & $\begin{array}{c}\text { Teaching } \\
\text { Approach }\end{array}$ \\
\hline Autonomy & 0.770 & & & & & \\
Competence & 0.693 & 0.822 & & & & \\
Motivation & 0.463 & 0.505 & 0.739 & & & \\
Relatedness & 0.608 & 0.600 & 0.634 & 0.782 & & \\
Self-Concept & 0.668 & 0.620 & 0.693 & 0.739 & 0.776 & \\
Teaching & 0.444 & 0.435 & 0.641 & 0.709 & 0.586 & 0.795 \\
Approach & & & & & & \\
\hline
\end{tabular}

Table 3 Heterotrait-Monotrait Ratio (HTMT)

\begin{tabular}{lccccc}
\hline Construct & Autonomy & $\begin{array}{c}\text { Compe- } \\
\text { tence }\end{array}$ & $\begin{array}{c}\text { Motiva- } \\
\text { tion }\end{array}$ & $\begin{array}{c}\text { Related- } \\
\text { ness }\end{array}$ & $\begin{array}{c}\text { Self- } \\
\text { Concept }\end{array}$ \\
\hline Autonomy & & & & & \\
Competence & 0.859 & & & & \\
Motivation & 0.585 & 0.602 & & & \\
Relatedness & 0.780 & 0.720 & 0.791 & & \\
Self-Concept & 0.926 & 0.802 & 0.936 & 1.001 & \\
Teaching Approach & 0.549 & 0.507 & 0.791 & 0.888 & 0.782 \\
\hline
\end{tabular}

The discriminant validity measures how unique the constructs dimension measures the construct without simply reflecting other variables. It is a means of validating construct and its uniqueness in measuring the constructs by its indicators although each construct reflects a portion of other construct. In most studies, the use of average variance extracted (AVE) is the common criteria for measuring discriminant validity although cross loading was equally effective for measuring discriminant validity. (Gerbing and Anderson, 1988). The result indicated that the square root of AVE for all construct were greater than the correlations between the construct and other constructs as indicated in Table 2. This proves the existence of discriminant validity. Furthermore, assessments of discriminant validity can be done better using the Heterotrait-Monotrait ratio (HTMT) since the use of Fornell-Larcker criteria is known to have some shortcomings. Using the HTMT method of assessing discriminant validity showed the existence of discriminant validity between the pair of constructs since the HTMT ratio for each pair of construct have a value below 0.85 and significant as shown in Table 3. Table 4 shows the significance of the various path coefficients, it was found that except the influence of students need of competence on student statistics self-concept all other path coefficients were statistically significant. 
Table 4 Test of Significance Structural Model

\begin{tabular}{lcccccc}
\hline Paths & $\begin{array}{l}\text { Original } \\
\text { Sample } \\
(\mathrm{O})\end{array}$ & $\begin{array}{l}\text { Sample } \\
\text { Mean (M) }\end{array}$ & $\begin{array}{l}\text { Standard } \\
\text { Deviation } \\
(\text { Stdev })\end{array}$ & $\begin{array}{l}\mathrm{T} \text { Statistics } \\
(|\mathrm{O} / \mathrm{Stdev}|)\end{array}$ & $\begin{array}{l}\mathrm{P} \\
\text { Values }\end{array}$ \\
\hline Autonomy -> Self-Concept & 0.320 & 0.324 & 0.093 & 3.450 & 0.001 \\
Competence -> Self-Concept & 0.096 & 0.098 & 0.097 & 0.983 & 0.325 \\
Relatedness -> Self-Concept & 0.509 & 0.509 & 0.066 & 7.724 & 0.000 \\
Self-Concept -> Motivation & 0.709 & 0.717 & 0.059 & 12.050 & 0.000 \\
CAST -> Autonomy & 0.433 & 0.451 & 0.088 & 4.916 & 0.000 \\
CAST-> Competence & 0.435 & 0.451 & 0.088 & 4.945 & 0.000 \\
CAST -> Relatedness & 0.692 & 0.701 & 0.052 & 13.241 & 0.000 \\
\hline
\end{tabular}

\section{Discussion}

Effect of constructivism on students' needs for competence, autonomy and relatedness

The study investigated the influence constructivism approach of statistics teaching (CAST) on students' needs for competence, autonomy and relatedness. The results of the study indicate direct relationship between constructivism approach to teaching and students' needs for competence, autonomy and relatedness. The results further explain that students' need for competence, autonomy and relatedness in statistics will improve when statistics teachers adopt teaching methods that allow students to take control of their learning. The path coefficients from constructivist teaching approach used (CAST) and students' need for competence, autonomy and relatedness were $0.435,0.433$ and 0.692 respectively. The results further indicated that the use of constructivism teaching statistics significantly influence students' need for competence, autonomy and relatedness with $p<0.001$. The study further explains that statistics teachers' adoption of constructivism approach in teaching will further the students' needs for competence, autonomy and relatedness. The results are consistent with the study by Deci \& Ryan, (2000) as they describe the need for competence, autonomy and relatedness as the three basic psychological needs for selfdetermination and motivation for learning statistics. The findings further supports other studies which suggest that basic psychological need of support learning motivation and student interest in statistics.

Effect of students needs for competence, autonomy and relatedness on students' statistics selfconcepts

In this section discussion covers results on how students' need for competence, autonomy and relatedness affects students' self-concept in statistics. The results from the path coefficients from the students' psychological need for competence to students' statistics self-concept, psychological need for autonomy to students' statistics self-concept and psychological need for relatedness to students' self-concept were $0.096,0.320$ and 0.509 respectively. The results indicate that there is positive relationship between students' psychological needs and students' statistics self-concept. The path coefficient from psychological need for competence to statistics self-concept was not statistically significant with $p>0.001$. The study however showed statistically significant relationship between students' need for autonomy and statistics self-concept as well as students need for relatedness and statistics self-concept $(0.509, \mathrm{p}<0.001)$. The study has indicated further the existence of direct proportionality between the students' needs for autonomy and students' 
Effect of the constructivists teaching method, undergraduate students' statistics self-concept and other psychological constructs in mediating their motivation for learning statistics

D. Y. Arthur

statistics self-concept as well as students' need for relatedness and students' statistics self-concept. The results imply further that, as students' need for autonomy and relatedness in improved their statistics self-concept increases same. The study reports and affirms from the results that, the need for autonomy and relatedness are potential factors for improving students' statistics self-concepts as they explain $63 \%$ of the total variance in students' statistics self-concepts as shown in Fig.4.

\section{Effect of students' statistics self-concepts on their motivation for learning statistics}

The study finally investigated the influence of constructivist approach of statistics teaching (CAST) on students' motivation for learning statistics as mediated by the need for competence, autonomy and relatedness as further mediated by the students' statistics self-concept. The result of the study shows that there is positive and significant relationship between the students' statistics self-concept and students' motivation for learning statistics. The result indicates a direct proportionality between students' statistics self-concept and students' motivation for studying statistics with path coefficient 0.709 and $p<0.001$. The result further implies that students' motivation for learning statistics will increase as they have higher self-concept for statistics. Adaptation of constructivism approach as a predictor of students' motivation for learning statistics can explain $50.8 \%$ of the total variance in students motivation for studying statistics as being mediated by psychological need for competence, relatedness and autonomy as well as students' statistics self-concept as presented in Fig 4.

\section{Conclusions}

The study after a careful scrutiny of the results concluded that the constructivism teaching approach positively and significantly influences students' psychological need for competence, autonomy and relatedness. The students' psychological need for autonomy and relatedness positively and significantly affects students' statistical self-concept. However, students' psychological need for competence though positively influences self-concept, it is not significant in contributing in predicting (68\%) students' statistics self-concept. The study further concluded that the teaching approach, psychological needs for competence autonomy and relatedness as well as students' statistics self-concept explains $48 \%$ of the total variance in students' motivation for learning statistics. Finally, the study concluded that students' statistic self-concepts positively and significantly affect students' motivation for learning statistics

\section{Recommendation}

The study provides justification for the mediatory effect of psychological needs and self-concept as predictor of students' motivation for studying statistics. The study has strong implication on mathematics and Statistics teachers to seek the integration of constructivism teaching method as well as seeking the psychological needs of the student. This will enhance the students' self-concept and further improve their motivation for learning statistics. It is the hope of this study that mathematics and Statistics educators, school authorities and government will use these findings as resource materials for progress of students' interest.

The study recommends the following further study to conduct to investigate how this model can tested for students who take statistics as an elective subject. This will help compare responses from students who take statistics as borrowed and non-elective subject as well as students who take statistics as elective. This will help validate the instrument for the assessment for student motivation for teaching statistics. 


\section{References}

Aunola, K., Viljaranta, J., Lehtinen, E., \& Nurmi, J. (2013). The role of maternal support of competence, autonomy and relatedness in children's interests and mastery orientation. Learning and Individual. Retrieved from http://www.sciencedirect.com/science/article/pii/S1041608013000204

Biehler, R. F., \& Snowmnan, J. (1986). Psychology Applied in Teaching (5th ed.). Boston: Houghton Mifflin Companay.

Boggiano, A. K., \& Barrett, M. (1985). Performance and motivational deficits of helplessness: The role of motivational orientaion. Journal of Personality and Social Psychology, 49, 17531761.

Bong, M., \& Skaalvik, E. (2003). Academic self-concept and self-efficacy: How different are they really? Educational Psychology Review.

Brooks, J. J. G., \& Brooks, M. G. (1999). In Search of Understanding: The Case for Constructivist Classrooms. Association for Supervision and Curriculum Development, 1-136. http://doi.org/10.1007/s13398-014-0173-7.2

Deci, E. L., \& Ryan, R. M. (2000). The "What" and "Why" of Goal Pursuits: Human Needs and the Self-Determination of Behavior. Psychological Inquiry, 11(4), 227-268. http://doi.org/10.1207/S15327965PLI1 104_01

Deci, E., Vallerand, R., Pelletier, L., \& Ryan, R. (1991). Motivation and Education: The SelfDetermination Perspective. Educational Psychologist, 26(3), 325-346. http://doi.org/10.1207/s15326985ep2603\&4_6

Edward, D., \& Ryan, R. (1985). Intrinsic Motivation and Self-Determination in Human Behavior. New York: Pantheon.

Frost, L. A., Hyde, J. S., \& Fennema, E. (1994). Gender, mathematics performance and mathematics-related attitudes and affect: A meta-analytic synthesis. International Journal of Educational Research, 21, 373-385. http://doi.org/10.1016/S0883-0355(06)80026-1

Githua, B. N., \& Mwangi, J. G. (2003). Students' mathematics self-concept and motivation to learn mathematics: relationship and gender differences among Kenya' s secondary-school students in Nairobi and Rift Valley provinces, 23, 487-499. http://doi.org/10.1016/S07380593(03)00025-7

Gottfried, A. E., Fleming, J. S., \& Gottfried, A. W. (1994). Role of parental motivational practices in children's academic intrinsic motivation and achievement. Journal of Educational, 86, 104-113.

Harter, S. (1981). A new self-report scale of intrinsic versus extrinsic orientation in the classroom: Motivational and informational components. Developmental Psychology, 17, 300-312.

Kim, J. S. (2005). The effects of a constructivist teaching approach on student academic achievement, self-concept, and learning strategies. Asia Pacific Education Review, 6(1), 719.

Lindberg, S. M., Hyde, J. S., Petersen, J. L., \& Linn, M. C. (2010). New trends in gender and mathematics performance: A meta-analysis. Psychological Bulletin, 136(6), 1123-1135. http://doi.org/10.1037/a0021276 
Effect of the constructivists teaching method, undergraduate students' statistics self-concept and other psychological constructs in mediating their motivation for learning statistics

D. Y. Arthur

Mohamed, L., \& Waheed, H. (2011). Secondary Students' Attitude towards Mathematics in a Selected School of Maldives. International Journal of Humanities and Social Science, 1(15).

Nie, Y., \& Lau, S. (2010). Differential relations of constructivist and didactic instruction to students' cognition, motivation, and achievement. Learning and Instruction, 20(5), 411-423. http://doi.org/10.1016/j.learninstruc.2009.04.002

Schunk, D. (1991). Self-Efficacy and Academic Motivation. Educational Psychologist, 26(3), 207-231. http://doi.org/10.1207/s15326985ep2603\&4_2

Skaalvik, S., \& Skaalvik, E. M. (2004). Gender Differences in Math and Verbal Self-Concept, Performance Expectations, and Motivation. Sex Roles, 50(3), 241-252. http://doi.org/10.1023/B:SERS.0000015555.40976.e6

Straus, M. A., \& Paschall, M. J. (2009). Corporal Punishment by Mothers and Development of Children's Cognitive Ability: A Longitudinal Study of Two Nationally Representative Age Cohorts. Journal of Aggression, Maltreatment \& Trauma, 18(5), 459-483. http://doi.org/10.1080/10926770903035168

Tella, A. (2007). The Impact of Motivation on Student' s Academic Achievement and Learning Outcomes in Mathematics among Secondary School Students in Nigeria. Learning, 3(2), $149-156$ 